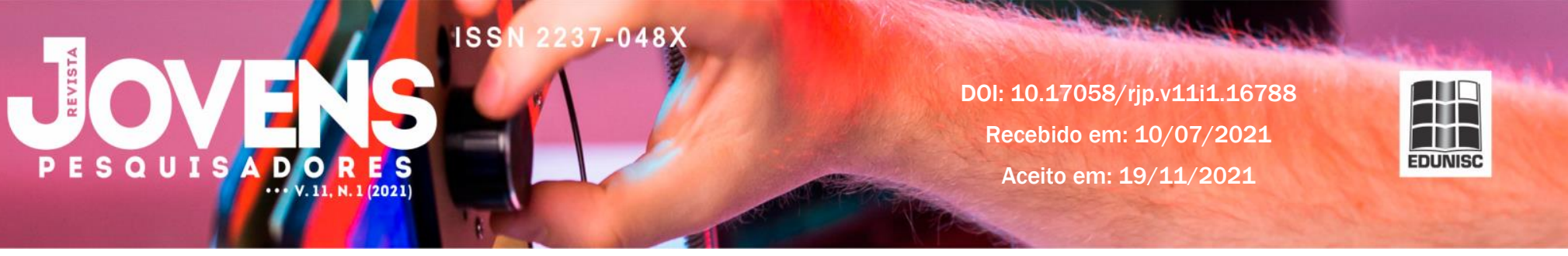

\title{
TRANSMISSÃO FAMILIAR DE SARS-CoV-2: 0 CUIDADO DEVE CONTINUAR EM CASA
}

\author{
GAUCINISKI, J.1; FAVERO, E.2; FISCHER, L.V.2.; PONTEL, M.L.K.3; GAEDKE, M.A.4; POSSUELO, L.G.4; \\ SCHNEIDER, A.P.H.4; CARNEIRO, M.4; KOEPP, J.4
}

PALAVRAS-CHAVE: SARS-CoV-2. COVID-19. Transmissão. Agrupamento Familiar.

\begin{abstract}
RESUMO
A doença COVID-19, causada pelo novo coronavírus SARS-CoV-2, iniciada na cidade de Wuhan, na China, alastrouse rapidamente pelo mundo provocando muitos óbitos. Esse estudo buscou identificar a prevalência de transmissão familiar de SARS-CoV-2 no município de Santa Cruz do Sul (RS). Trata-se de um recorte de um estudo transversal de base populacional que mensurou a soroprevalência de SARS-CoV-2 na região central do estado do Rio Grande do Sul, Brasil. 0 processo constitui-se de uma amostragem sistemática dos setores censitários, seguido de sorteio aleatório simples dos domicílios em cada setor conforme tamanho de amostra estipulado. Em cada domicílio uma pessoa foi aleatoriamente sorteada e convidada a participar do estudo, realizando exame de teste de diagnóstico rápido para a detecção qualitativa de anticorpos IgG e IgM contra SARS-CoV-2. Havendo teste reator IgM, todos os moradores presentes no domicílio no momento da coleta foram testados. Um formulário online foi utilizado para a coleta de dados, com informações sobre características sociodemográficas e questões ligadas à saúde do entrevistado. Totalizou-se 1.158 pessoas entrevistadas, com média de idade de 49,5 $\pm 19,0$ anos, sendo $62,7 \%$ do sexo feminino e $80,4 \%$ residindo na zona urbana. Dentre os 33 casos identificados com testes rápidos reatores, 23 tinham familiares presentes no momento da coleta, totalizando 46 familiares testados. Os achados sugerem que a prevalência de transmissão familiar seja de $47,8 \%$, demonstrando ser essencial conscientizar a população frente aos cuidados que devem ser tomados para evitar a transmissão do SARS-CoV-2, principalmente em meios compartilhados, como no ambiente familiar.
\end{abstract}

\section{FAMILY TRANSMISSION SARS-CoV-2: CARE MUST CONTINUE AT HOME}

KEYWORDS: SARS-CoV-2. COVID-19. Transmission. Family Cluster.

\begin{abstract}
The COVID-19 disease caused by the new coronavirus SARS-CoV-2, which occurred in the city of Wuhan, in China, spread rapidly around the world causing many deaths. This study sought to identify a prevalence of familial transmission of SARS-CoV-2 in the municipality of Santa Cruz do Sul (RS). It is an excerpt from a cross-sectional population-based study that measured the seroprevalence of SARS-CoV-2 in the central region of the state of Rio Grande do Sul, Brazil. The process consists of a systematic sampling of the census sectors, followed by a simple random drawing of households in each sector, according to the stipulated sample size. In each household, a person was randomly selected and invited to participate in the study, performing a rapid diagnostic test for a qualitative detection of IgG and IgM against SARS-CoV-2. If there is an IgM reagent test, all residents present in the household at the time of collection were tested. An online form was used to collect data, with information on the sociodemographic characteristics and health issues of the interviewee. A total of 1158 people were interviewed, with an average age of $49.5 \pm 19,0$ years, with $62.7 \%$ being female and $80.4 \%$ living in the urban area. Among the 33 cases identified with rapid reactor tests, 23 family members were present at the time of collection, totaling 46 family members tested. The findings found that the prevalence of family transmission is $47.8 \%$, demonstrating that it is essential to raise awareness among the population regarding the care that must be taken to avoid the transmission of SARS-CoV-2, especially in shared environments, such as in the family environment.
\end{abstract}

\footnotetext{
${ }^{1}$ Acadêmico do Curso de Medicina da Universidade de Santa Cruz do Sul (UNISC) - RS.

2 Acadêmico do Curso de Odontologia da Universidade de Santa Cruz do Sul (UNISC) - RS.

${ }^{3}$ Acadêmica do Curso de Biomedicina da Universidade de Santa Cruz do Sul (UNISC) - RS.

${ }^{4}$ Docente da Universidade de Santa Cruz do Sul (UNISC) - RS. E-mail: brjaninek@unisc.br
} 


\section{INTRODUÇÃO}

Identificada em pacientes hospitalizados na cidade de Wuhan, China, a síndrome respiratória aguda grave coronavírus 2 (COVID-19) causada pelo vírus SARS-CoV-2, se disseminou pelo país asiático entre dezembro de 2019 e janeiro de 2020 (ZHU et al., 2020; GUOUQING et al., 2020). A propagação da pandemia mundialmente, declarada pela Organização Mundial da Saúde (OMS) em março de 2020, resultou em bloqueios globais no esforço de "nivelar a curva" de contágio e não sobrecarregar as instituições de saúde (LAU et al., 2020). Um ano após anunciada a pandemia, há cerca de 185.000 .000 casos confirmados e mais de 4.000 .000 mortes em todo o mundo decorrentes da nova doença (OMS, 2021), demonstrando seu elevado poder de transmissibilidade e mortalidade em relação a outras enfermidades.

O caminho para interromper a cadeia de transmissão que se mostrou eficiente desde o início foi 0 isolamento das pessoas infectadas e rastreamento daqueles com quem elas interagiram (LARSEN et al., 2020). 0 vírus, que é transmitido por meio da inoculação de secreções respiratórias, gotículas expelidas pela tosse, saliva, fômites contaminados como, por exemplo, maçanetas, corrimãos, mesas, apresenta menor taxa de transmissão de pessoa para pessoa com medidas de distanciamento social e cuidados de higiene pessoal (CANDIDO et al., 2020; LAU et al., 2020; WHO, 2020; LI et al., 2020).

Nesse sentido, diferentes medidas de prevenção e controle da doença foram tomadas pelas autoridades sanitárias brasileiras, as quais se diferenciam de uma região para outra do país, sendo que a medida mais difundida pelas autoridades foi a prática do isolamento social (PIRES, 2020). 0 quadro nacional apresentado no início da pandemia mostrava que cada pessoa infectada transmitia o vírus para outras três pessoas e, após a adoção de medidas de restrição, cada infectado passou a contaminar menos de duas pessoas (CANDIDO et al., 2020). 0 maior índice de isolamento social (IIS) no território brasileiro foi registrado em 22 de março de 2020 (62,2\%). Em 09 de junho do mesmo ano, o país apresentou IIS de 38,2\%, demonstrando que a população brasileira, com o passar do tempo, passou a se expor mais ao risco de contágio (AQUINO et al., 2020).

Salienta-se que as estratégias de prevenção ao SARS-CoV-2 demandam uma atenção especial no ambiente familiar, em que o contato interpessoal assume uma dinâmica singular embasada no coletivo. A taxa de ataque secundário, definida como a probabilidade de que uma infecção ocorra entre pessoas suscetíveis dentro de um grupo específico (ou seja, família ou contatos próximos), fornece uma indicação de como as interações sociais reportam ao risco de transmissão (LIU, EGGO, KUCHARSKI, 2020). Ademais, o tempo de exposição a um indivíduo infectado amplifica a chance de contrair a doença, estando os cônjuges mais suscetíveis ao contágio com base na dinâmica familiar (Ll et al., 2020).

Diante do exposto, a transmissão domiciliar entre familiares se torna um ponto importante a ser analisado. Essa interação social corrobora na formação da dinâmica geral da propagação da COVID-19 e no estabelecimento da eficácia das estratégias de mitigação (LIU, EGGO, KUCHARSKI, 2020). Apesar de permanecer pouco investigada, a chance de exposição à infecção dentro do modelo domiciliar pode ser maior do que na comunidade e no nível populacional, assim como a probabilidade de transmissão da doença no âmbito familiar (LI et al., 2020; LIU, EGGO, KUCHARSKI, 2020). Neste contexto, este estudo teve como objetivo identificar a prevalência de transmissão familiar de SARS-CoV-2 no município de Santa Cruz do Sul. 


\section{REFERENCIAL TEÓRICO}

O SARS-CoV-2 caracteriza-se por ser um vírus com afinidade pelo tecido pulmonar e elevado potencial de transmissão entre indivíduos por meio de secreções do trato respiratório, especialmente na forma de gotículas produzidas pela tosse, espirro ou pela fala, bem como através de superfícies contaminadas e fômites (TRIGGLE et al., 2021). Sua alta taxa de disseminação foi constatada no início da pandemia de COVID-19, quando o número reprodutivo básico - dado que avalia a quantidade média de novas infecções a partir de um indivíduo - era estimado em 3,28 (LIU et al., 2020). Sabe-se, ainda, que sua prevalência e transmissibilidade são consideravelmente mais altas que dos vírus SARS-CoV e MERS-CoV, embora os índices de mortalidade e gravidade sejam inferiores (SINGH et al., 2021). Atualmente, os dados que envolvem a COVID-19 são notáveis, considerando que o número de novos casos reportados em 24 horas chegou a ultrapassar a marca de 895.000, em nível mundial, no dia 23 de abril de 2021. 0 Brasil encontra-se em posição de destaque nesse índice, tendo registrado mais de 115.000 novos casos reportados no dia 25 de junho de 2021 e superado o número de 500.000 óbitos desde o início da pandemia (OMS, 2021).

Uma vez infectado, o indivíduo torna-se agente transmissor capaz de propagar a doença de modo exponencial, tendo em vista que aproximadamente $80 \%$ dos portadores apresentam-se assintomáticos ou desenvolvem sintomas leves (TRIGGLE et al., 2021). Tais indivíduos, muitas vezes, não possuem consciência do seu papel no ciclo da doença, potencializando, dessa forma, a cadeia de transmissão. Nesse contexto, observouse que a carga viral é semelhante em indivíduos sintomáticos e assintomáticos, o que corrobora a capacidade de transmissão destes. Ou seja, mesmo o infectado sintomático é capaz de transmitir o vírus ainda durante o seu período de incubação - tempo decorrido entre o contágio e o início dos sintomas - que corresponde, em média, a 5-6 dias, mas pode chegar a duas semanas, fato que contribui para a dificuldade no rastreamento da doença (OMS, 2020).

Como estratégia de controle da disseminação do SARS-CoV-2, foram preconizadas medidas de higiene e proteção individual, como a lavagem das mãos ou uso de álcool gel e máscara, associadas ao distanciamento social físico, com recomendação de uma distância mínima de 1 a 2 metros entre indivíduos em espaços sociais compartilhados (OMS, 2021; QURESHI et al., 2020). Estudos demonstram que a velocidade de transmissão é menor com a instauração do lockdown, que compreende a prática do distanciamento em larga escala complementada pela restrição de movimento, ainda que tal medida apresente impactos significativos no campo econômico (OPAS, 2020; LAU et al., 2020). Faz-se, assim, de suma importância investigar a prevalência da transmissão de SARS-CoV-2 no ambiente familiar, a fim de compreender o impacto dessa dinâmica de convívio na propagação da COVID-19.

\section{MATERIAIS E MÉTODOS}

Trata-se de estudo do tipo transversal de base populacional com amostra representativa da população do Vale do Rio Pardo, Rio Grande do Sul. É um recorte da pesquisa "Estudo de Soroprevalência de SARS-CoV-2 na Região do Vale do Rio Pardo (COVID-VRP)", que envolveu quatorze municípios que compõem o Consórcio 
Intermunicipal de Serviços do Vale do Rio Pardo. Foram incluídos os dados da população de Santa Cruz do Sul (RS) coletados em três etapas da pesquisa.

O cálculo de tamanho da amostra foi realizado através da fórmula da amostragem aleatória simples para estimação de proporções, considerando um nível de confiança de $95 \%$ e uma margem de erro de 5 pontos percentuais. As coletas ocorreram nos finais de semana com intervalos quinzenais, no período compreendido entre 1 de agosto e 13 de setembro de 2020 (da $31^{\circ}$ até a $38^{\circ}$ semana do calendário epidemiológico). Em cada etapa a amostra foi composta por 386 indivíduos, totalizando 1.158 indivíduos pesquisados em Santa Cruz do Sul.

0 processo de amostragem foi realizado por múltiplos estágios, incluindo amostragem sistemática dos setores censitários, em que foi sorteado $25 \%$ do número de setores censitários do município. Após foi realizado sorteio aleatório simples dos domicílios a serem abordados em cada setor urbano conforme o tamanho de amostra estipulado. Para os setores censitários rurais foi sorteado apenas o primeiro domicílio a ser visitado, de forma que os demais foram selecionados a partir deste, sempre abordando o próximo que fosse encontrado seguindo na estrada à direita da primeira coleta, considerando ambos os lados da estrada.

Os endereços que foram pesquisados em cada setor sorteado foram obtidos a partir do Cadastro Nacional de Endereços para Fins Estatísticos (CNEFE) do IBGE, Censo de 2010. Em cada domicílio uma pessoa foi aleatoriamente sorteada e convidada a participar do estudo. A partir da segunda rodada, os domicílios participantes nos setores censitários urbanos foram sempre selecionados de forma sistemática, partindo do quinto domicílio à direita em relação ao último selecionado na rodada anterior. Nas situações em que o domicílio selecionado não correspondia ao endereço residencial ou que não havia ninguém no momento da entrevista ou diante de recusa em participar do estudo, o mesmo foi substituído pelo próximo domicílio à direita que atendesse aos critérios de inclusão. Para os setores censitários de zona rural, em todas as etapas foi sorteado um novo endereço como ponto de partida para as coletas.

A coleta de dados, que incluiu a realização do teste rápido sorológico para SARS-CoV-2 e aplicação de um questionário, foi realizada por entrevistadores selecionados entre estudantes dos cursos superiores da área da saúde da UNISC. Todos os entrevistadores receberam treinamento sobre a realização do Teste Rápido (TR), normas de biossegurança, bem como aplicação do questionário antes de cada etapa. Foi utilizado um TR imunocromatográfico qualitativo (Leccurate do fabricante Beijing Lepu Medical Techonology CO LTD) contra o SARS-CoV-2 em amostra de sangue coletada por punção digital. Para a aplicação do questionário com finalidade de caracterização da amostra, foi utilizado o software Epi InfoTM (CDC, US), versão para dispositivo móvel. Em caso de teste rápido reator, todos os moradores do domicílio presentes no momento da coleta de dados foram convidados a realizar o teste rápido. A vigilância epidemiológica do município foi comunicada dos resultados positivos.

As variáveis analisadas para caracterização da amostra foram sexo, faixa etária, escolaridade, renda familiar mensal (categorização em salários mínimos) e zona de moradia (urbana e rural). Para este estudo a variável de desfecho foi a prevalência de teste rápido reator entre os familiares testados.

Foi realizada análise estatística descritiva para caracterização da amostra e demais variáveis pesquisadas no software Stata ${ }^{\circledR} 14.0$ (StataCorp. 2013. Stata Statistical Software: Release 14. College Station, TX: StataCorp 
LP) versão 11. Os resultados foram descritos em frequências absolutas e relativas por se tratarem de variáveis categóricas.

A pesquisa foi aprovada pelo Comitê de Ética em Pesquisa da UNISC sob o parecer número 4.193.725 e CAAE 31625220.2.0000.5343. Todos os participantes receberam informações detalhadas sobre os objetivos da pesquisa, os riscos e os benefícios de sua participação e assinaram o Termo de Consentimento Livre e Esclarecido.

\section{RESULTADOS E DISCUSSÃO}

A amostra totalizou 1.158 indivíduos, com idade média de 49,6 $\pm 19,0$ anos. As características predominantes dos participantes foram: sexo feminino $(62,72 \%)$, população adulta economicamente ativa na faixa etária de 20 a 59 anos (58,7\%), ensino fundamental completo (40,35\%), renda familiar entre $\mathrm{R} \$ 1.046,00$ até $\mathrm{R} \$ 3.135,00$ (43,92\%) e moradia em zona urbana (80,40\%), conforme os dados apresentados na Tabela 1.

A maior frequência de mulheres na amostra está de acordo com a característica demográfica do município de Santa Cruz do Sul, que apresenta um percentual ligeiramente maior de mulheres (51,90\%) do que de homens (48,10\%) (CENSO, 2010). Entretanto, a diferença observada em nosso estudo, apesar de sustentada pela aleatoriedade inerente à metodologia, pode também estar atrelada a fatores culturais e socioeconômicos exacerbados durante a pandemia, como o fato de as mulheres estarem mais presentes em casa no momento da abordagem.

Tabela 1. Descrição da amostra conforme variáveis demográficas e socioeconômicas ( $\mathbf{N}=1158)$.

\begin{tabular}{lcc} 
Variáveis & \multicolumn{2}{c}{ Total } \\
\cline { 2 - 3 } & $n$ & $\%$ \\
\hline Sexo (n 1156) & & \\
Masculino & 431 & 37,2 \\
Feminino & 725 & 62,7 \\
Faixa etária ( $\mathrm{n} 1136)$ & & \\
0 a 19 anos & 75 & 6,6 \\
20 a 59 anos & 662 & 58,7 \\
$\geq 60$ anos & 399 & 34,6 \\
Escolaridade ( $\mathrm{n} 1150)$ & & \\
Analfabeto / não estudou & 18 & 1,57 \\
Educação infantil & 48 & 4,17 \\
Fundamental & 464 & 40,3 \\
Ensino médio & 339 & 29,4 \\
Superior e Pós-graduação & 281 & 24,4 \\
Renda familiar (n 1118) & & \\
Até $R \$ 1.045,00$ & 137 & 12,2 \\
De $R \$$ 1.046,00 até $R \$ 3.135,00$ & 491 & 43,9
\end{tabular}




\begin{tabular}{lcc} 
De $R \$ 3.136,00$ até $R \$ 6.270,00$ & 289 & 25,8 \\
Mais de $R \$ 6.271,00$ & 125 & 11,1 \\
Não quis informar & 76 & 6,8 \\
Zona de moradia ( $n$ 1158) & & \\
Urbana & 931 & 80,4 \\
Rural & 227 & 19,6 \\
\hline a Perda máxima $=40$ participantes sem informação de renda familiar
\end{tabular}

Um total de $33(2,85 \%)$ entrevistados tiveram TR reator; desses indivíduos, 23 (1,99\%) estavam acompanhados de familiares no momento da pesquisa, totalizando 46 familiares incluídos na testagem (média de 2 familiares testados por residência). A taxa de transmissão de caso reator para familiar foi de 47,80\%, ou seja, dos 23 casos, 11 familiares apresentaram teste reator. A prevalência de reatores considerando todos os familiares testados foi de $23,91 \%$ (Figura 1 ).

Figura 1. Prevalência da transmissão familiar.

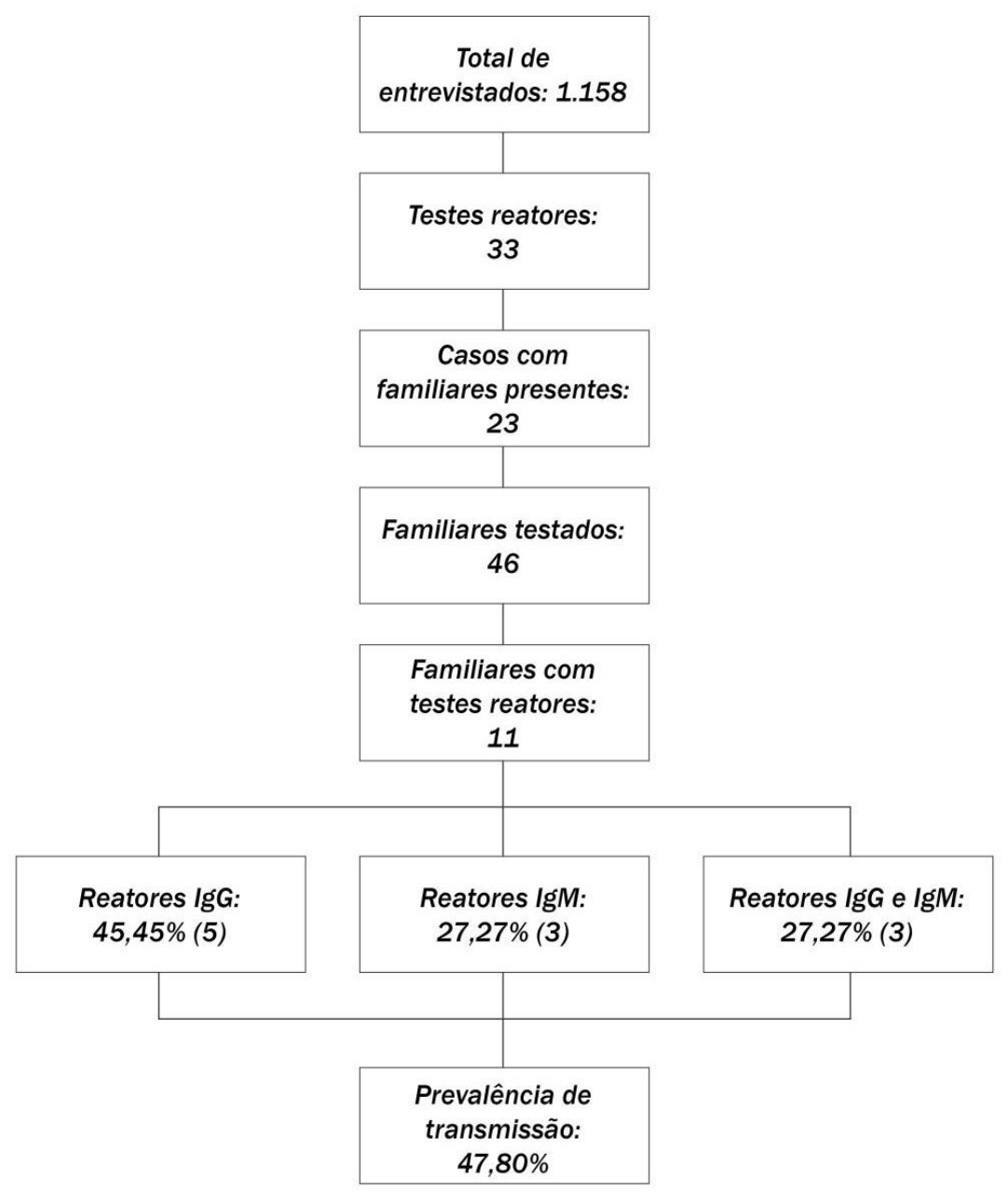

A taxa de prevalência encontrada no presente estudo foi maior do que a identificada por Li et al. (2020) em pesquisa realizada na China, a qual constatou uma taxa de $16,3 \%$ dos contatos domiciliares infectados. 0 
mesmo estudo ainda verificou a inexistência de transmissão secundária por parte dos indivíduos que adotaram medidas preventivas assim que identificados os sintomas iniciais de COVID-19, incluindo o uso de máscara e afastamento do infectado em relação aos demais moradores. Wang et al. (2020) encontraram uma prevalência de $30 \%$ de familiares infectados a partir de casos positivos em Wuhan, na China. Essa discrepância nos dados pode estar relacionada com as diferenças socioculturais entre os países, que impactam diretamente no âmbito da saúde coletiva. Diferente da China, que detém um posicionamento rígido no que concerne ao descumprimento de normas sociais, o Brasil é culturalmente mais flexível, estando os habitantes mais propensos a violar as regras estabelecidas (GELFANT et al., 2021). Assume-se, dessa forma, que a população brasileira adote com certa negligência as condutas orientadas no contexto da pandemia em curso, acarretando consequências diretas no âmbito familiar. Essa premissa é apoiada pelos elevados índices de novos casos diagnosticados por dia no Brasil.

Ressalta-se que houve uma importante diferença entre a prevalência de testes reatores encontrados na amostra total da pesquisa $(2,85 \%)$ e a prevalência de transmissão familiar $(47,80 \%)$, o que ratifica a influência de um modelo de convívio estruturado em ambiente compartilhado como facilitador na propagação do SARSCoV-2. No estudo realizado por Cao et al. (2020), observou-se uma média de dois casos novos para cada caso índice no contexto familiar, a partir de um número reprodutivo básico equivalente a 2,06. Neste sentido, postulase que, quando está em casa, o indivíduo acabe por flexibilizar os cuidados necessários para a prevenção da COVID-19, tais como higienização das mãos e de objetos, presumindo um nível de segurança que muitas vezes não corresponde à realidade, especialmente em um contexto no qual algum morador exerce atividade regular fora da residência, fato que aumenta a chance de contato com o vírus e consequente transmissão. Assim, 0 contato interpessoal entre familiares configura uma importante via de transmissão do SARS-CoV-2, principalmente em regiões que abrigam famílias numerosas e onde as medidas de quarentena não são aplicadas de forma adequada (WANG et al., 2020).

Entende-se, dessa forma, que a família assume um papel paradoxal no contexto da pandemia. Ao passo que se configura como um refúgio para as possíveis mazelas psicológicas do indivíduo, compreende, também, um obstáculo no que tange ao cumprimento das condutas de isolamento social. Observa-se, nesse contexto, que as medidas adotadas para controle da transmissão viral, como o fechamento de escolas e a adaptação de atividades profissionais para a modalidade home office, acabam, invariavelmente, aproximando os membros familiares que residem sob o mesmo teto à medida que os afasta do meio social. Estes dois ambientes não podem ser dissociados na pauta dos cuidados profiláticos - a partir do momento em que o indivíduo sai de casa e aumenta o seu grau de exposição ao vírus, produz um consequente aumento no risco de infecção para as pessoas com quem convive, mesmo que estas permaneçam somente no domicílio. Dessa forma, as precauções devem ser mantidas dentro da residência, tendo em vista que esta representa uma extensão do meio externo e se torna passível de potencializar a transmissão da COVID-19, como observado na prevalência identificada em nosso trabalho.

Nesse prisma, deve-se considerar que o combate à COVID-19 estrutura-se também de acordo com as especificidades de cada país, considerando características socioeconômicas e culturais. Países que não apresentam um histórico relevante de desastres naturais ou prevalência de doenças tendem a encarar situações ameaçadoras com certo otimismo, baseando-se em um modelo normativo mais permissivo em comparação aos países que já enfrentaram tais mazelas (GELFANT et al., 2021). Esse contexto pode ser aplicado ao Brasil, que 
apresenta, da mesma forma, obstáculos intrínsecos às suas problemáticas sociais. Como observado nos países emergentes, o descumprimento das orientações no âmbito da saúde é favorecido em um contexto de educação precária inerente à situação de pobreza extrema, tendo em vista, também, a impossibilidade do sustento familiar se adotadas as estratégias de quarentena (ESTRELA et al., 2020). Somado a isso, famílias de classes mais baixas residem, por vezes, em uma moradia cuja configuração não permite medidas restritivas entre os familiares, sendo usual o compartilhamento de um mesmo cômodo para habitação. Tal cenário representa uma barreira no manejo de uma eventual infecção pelo SARS-CoV-2.

O isolamento domiciliar é responsável por retardar a transmissão do vírus e diminuir o número de pessoas que procuram o atendimento hospitalar, no entanto, isso não impede que ocorra a transmissão do SARS-CoV-2 entre os residentes no domicílio, considerando o convívio, os cuidados diretos e os vínculos afetivos entre pais e filhos (SILVA et al., 2020). Segundo a OMS (2020), as recomendações para se realizar o isolamento domiciliar é manter o indivíduo infectado em um quarto individual e bem ventilado com circulação limitada aos demais cômodos, o que em muitos casos não é possível em função das condições da residência da família. Além disso, é preconizado o uso contínuo da máscara cirúrgica e manter o uso individual de talheres, pratos, bebidas, toalhas de papel descartável e roupas de cama individuais. A higienização destes itens deve ser realizada continuamente com água e sabão e álcool $70 \%$. Todo esse cuidado exige da família uma preparação diferente da dinâmica domiciliar.

Em relação à desinfecção das superfícies, como mesas, cadeiras, vaso sanitário, pia e outros móveis do quarto, deve ser realizada diariamente, pelo menos uma vez ao dia, com desinfetante doméstico ou solução de água sanitária com a concentração do princípio de cloro ativo de 2 a 2,5\% em um litro de água, e a pessoa que irá realizar a limpeza deverá usar luvas descartáveis e aventais de proteção, descartando-os logo após o ato (OMS, 2020). Mais uma vez, esbarra-se na questão financeira, sendo que nem todos possuem poder aquisitivo para adquirir estes materiais de proteção individual e produtos de higiene.

Ressalta-se que as medidas profiláticas preconizadas representam um paradigma no que tange ao convívio familiar, que é alicerçado no compartilhamento de ambientes e utensílios. Este tópico torna-se relevante à medida que se observa a capacidade de sobrevivência do vírus por longos períodos em determinados materiais, podendo chegar a 72 horas em plástico e aço inoxidável (OPAS, 2020). Nesse sentido, o tempo de exposição ao vírus é uma variável que aumenta o risco de infecção, de forma que o contato prolongado entre um indivíduo infectado e os demais moradores contribui para a propagação viral. Nesse contexto, além dos cuidados de higiene, orienta-se manter os ambientes ventilados e evitar visitas a familiares idosos ou portadores de doenças que os classifiquem como grupo de risco (OPAS, 2020; STAWICKI et al., 2020).

Pondera-se como limitações deste estudo o fato de que testes rápidos sorológicos não podem ser considerados padrão ouro para diagnóstico da doença, e que mesmo apresentando bons resultados de sensibilidade e especificidade, há margem para resultados tanto falsos positivos quanto falsos negativos.

\section{CONCLUSÃO}

0 presente estudo sugere que a interação familiar é um facilitador para a transmissão do vírus SARS-CoV2. Deste modo, conscientizar a população em relação aos cuidados profiláticos acerca da COVID-19 é 
imprescindível para que os índices observados no atual estágio da pandemia sejam modificados. A alta taxa de transmissibilidade do vírus demonstrou-se um fator agravante a ser considerado, especialmente no ambiente familiar, que é fundamentado na prática do compartilhamento. Torna-se imperioso, portanto, que as medidas de higiene, proteção individual e distanciamento social sejam praticadas por todos os indivíduos, em todos os âmbitos sociais, a fim de evitar a transmissão do vírus, considerando qualquer nível de contato interpessoal.

\section{AGRADECIMENTOS}

Os autores agradecem ao CISVALE (Consórcio Intermunicipal de Serviços do Vale do Rio Pardo), à 13a Coordenadoria Regional de Saúde do Rio Grande do Sul, às Prefeituras Municipais de Boqueirão do Leão, Candelária, Gramado Xavier, Herveiras, Mato Leitão, Pantano Grande, Passo do Sobrado, Rio Pardo, Santa Cruz do Sul, Sinimbu, Vale do Sol, Vale Verde, Venâncio Aires e Vera Cruz, e à Philip Morris Brasil, pelo apoio ao desenvolvimento desta pesquisa.

\section{REFERÊNCIAS}

AQUINO, E.M. L. et al. Medidas de distanciamento social no controle da pandemia de COVID-19: potenciais impactos e desafios no Brasil. Ciênc. saúde coletiva, Rio de Janeiro, v. 25, supl. 1, p. 2423-2446, 2020 .Disponivel em: <http://www.scielo.br/scielo.php?script=sci_arttext\&pid=S1413-

81232020006702423\&lng=en\&nrm=iso>. Acesso em: 25 de Março de 2021.

CANDIDO D.S. et al. Evolution and epidemic spread of SARS-CoV-2 in Brazil. Science, Vol. 369, Issue 6508, pp. 1255-1260, 2020. Disponível em: <https://science.sciencemag.org/content/369/6508/1255>. Acesso em: 23 de Março de 2021.

CAO, Y et al. Transmission dynamics of COVID-19 among index case family clusters in Beijing, China. Epidemiology and Infection, 149, E74, 2020. Disponível em: <https://www.cambridge.org/core/journals/epidemiology-and-infection/article/transmission-dynamics-ofcovid19-among-index-case-family-clusters-in-beijing-china/8AA34E5C451330E7B0F5F693160B9180>. Acesso em: 25 de Março de 2021.

ESTRELA, F. M. et al. Pandemia da Covid 19: refletindo as vulnerabilidades a luz do gênero, raça e classe. Ciênc. saúde coletiva, Rio de Janeiro, v. 25, n. 9, p. 3431-3436, Sept. 2020. Disponível em: <http://www.scielo.br/scielo.php?script=sci_arttext\&pid=S1413-81232020000903431\&Ing=en\&nrm=iso>. Acesso em 18 de Abril de 2021.

GELFANT, M.J. et al. The relationship between cultural tightness-looseness and COVID-19 cases and deaths: a global analys. THE LANCED. Vol. 5, ISSUE 3, E135-E144, 2021. Disponível em: <https://www.thelancet.com/journals/lanplh/article/PIIS2542-5196(20)30301-6/fulltext\#articlelnformation>. Acesso em: 25 de Março de 2021.

GUOQING, Q. et al. COVID-19 Transmission Within a Family Cluster by Presymptomatic Carriers in China. Clinical Infectious Diseases, Volume 71, Issue 15, 1 August 2020, Pages 861-862. Disponível em: <https://academic.oup.com/cid/article/71/15/861/5810900>. Acesso em: 21 de Março de 2021.

IBGE. Instituto Brasileiro de Geografia e Estatística. Sinopse do Censo Demográfico 2010, Rio Grande do Sul Razão de sexo, população de homens e mulheres, segundo os municípios - 2010. Disponível em: <https://censo2010.ibge.gov.br/sinopse/index.php?dados=2R\&uf=43>. Acesso em: 17 de Abril de 2021. 
LARSEN, D. et al. A review of infectious disease surveillance to inform public health action against the novel coronavirus SARS-CoV-2. SocArXiv, 2020. Disponível em: <https://osf.io/preprints/socarxiv/uwdr6/>. Acesso em: 23 de Março de 2021.

LAU, H. et al. The positive impact of lockdown in Wuhan on containing the COVID-19 outbreak in China. Journal of travel medicine, 2020. Disponível em: <https://pubmed.ncbi.nlm.nih.gov/32181488/>. Acesso em: 21 de Março de 2021.

LI, W. et al. Characteristics of Household Transmission of COVID-19. Clinical infectious diseases: an official publication of the Infectious Diseases Society of America, 71(8), 1943-1946, 2020. Disponivel em: <https://pubmed.ncbi.nlm.nih.gov/32301964/>. Acesso em: 23 de Março de 2021.

LIU, Y.; EGGO, R.RM.; KUCHARSKI A.J. Secondary attack rate and superspreading events for SARS-CoV-2. The Lancet, Vol. 395, n. 10227, p839-920, e46-e51. Disponível em:

<https://www.thelancet.com/journals/lancet/article/PIIS0140-6736(20)30462-1/fulltext\#articlelnformation>. Acesso em: 25 de Março de 2021.

LIU, Y. et al. The reproductive number of COVID-19 is higher compared to SARS coronavirus. Journal of Travel Medicine, 2020. Disponível em: <https://www.ncbi.nlm.nih.gov/pmc/articles/PMC7074654/>. Acesso em: 22 de Março de 2021.

OPAS. Organização Pan-Americana da Saúde/ Organização Mundial da Saúde (OMS). Folha informativa COVID19 - Escritório da OPAS e da OMS no Brasil. Organização Pan-Americana de Saúde, atualização 12 de fevereiro de 2020. Disponível em: <https://www.paho.org/pt/covid19>. Acesso em 23 de Março de 2021.

PIRES, R.R.C. Nota Técnica n. 33 (Diest): Os Efeitos sobre grupos sociais e territórios vulnerabilizados das medidas de enfrentamento à crise sanitária da Covid-19: propostas para o aperfeiçoamento da ação pública. Instituto de Pesquisa Econômica Aplicada (Ipea), 2020. Disponível em: <http://repositorio.ipea.gov.br/handle/11058/9839>. Acesso em: 23 de Março de 2021.

QURESHI, Z. et al.What is the evidence to support the 2-metre social distancing rule to reduce COVID-19 transmission?. The centre for Evidence-Based Medicine. Junho, 2020. Disponível em:

<https://www.cebm.net/covid-19/what-is-the-evidence-to-support-the-2-metre-social-distancing-rule-to-reducecovid-19-transmission/>. Acesso em: 17 de Abril de 2021.

SILVA, J. H. et al. Descrição de um cluster da COVID-19: o isolamento e a testagem em assintomáticos como estratégias de prevenção da disseminação local em Mato Grosso.. Epidemiologia e Serviços de Saúde, v. 29, n. 4, 2020. Disponível em: <https://doi.org/10.5123/S1679-49742020000400005>. Acesso em: 20 de Abril de 2021.

SINGH, R. et al. COVID-19: Current knowledge in clinical features, immunological responses, and vaccine development. FASEB journal: official publication of the Federation of American Societies for Experimental Biology vol. 35,3 (2021): e21409. 2021. Disponível em:

<https://www.ncbi.nlm.nih.gov/pmc/articles/PMC7898934/?report=classic>. Acesso em 23 de Março de 2021.

STAWICKI, S. P. et al. The 2019-2020 Novel Coronavirus (Severe Acute Respiratory Syndrome Coronavirus 2) Pandemic: A Joint American College of Academic International Medicine-World Academic Council of Emergency Medicine Multidisciplinary COVID-19 Working Group Consensus Paper. Journal of global infectious diseases, 12(2), 47-93. Disponível em: <https://www.ncbi.nlm.nih.gov/pmc/articles/PMC7384689/>. Acesso em 24 de Março de 2021.

TRIGGLE, C.R. et al. A Comprehensive Review of Viral Characteristics, Transmission, Pathophysiology, Immune Response, and Management of SARS-CoV-2 and COVID-19 as a Basis for Controlling the Pandemic. Frontiers in immunology vol. 12 631139. 26 Feb. 2021, Disponível em:

<https://www.ncbi.nlm.nih.gov/pmc/articles/PMC7952616/>. Acesso em 22 de Março de 2021.

WANG, Z. et al. Household transmission of SARS-CoV-2. The Journal of infection, 81(1), 179-182, 2020. Disponível em: <https://doi.org/10.1016/j.jinf.2020.03.040>. Acesso em: 17 de Abril de 2021. 
WHO. Modes of transmission of virus causing COVID-19: implications for IPC precaution recommendations. Word Health Organization, 2020. Disponível em: <https://www.who.int/news-room/commentaries/detail/modes-oftransmission-of-virus-causing-covid-19-implications-for-ipc-precaution-recommendations >. Acesso em: 23 de Março de 2021.

WHO. World Health Organization. Home care for patients with suspected novel coronavirus (COVID-19) infection presenting with mild symptoms, and management of their contacts Interim guidance 04, March 17, 2020. Geneva: WHO; 2020. Disponível em:<https://apps.who.int/iris/rest/bitstreams/1272420/retrieve >. Acesso em 28 de Março de 2021.

WHO. World Health Organization Coronavirus disease situation dashboard presents official daily count. Word Health Organization, 2021. Disponível em: <https://covid19.who.int/>. Acesso em 08 de Julho de 2021.

WÖLFEL R. et al. Virological assessment of hospitalized patients with COVID-2019 Nature. 2020;581(7809):465469. Disponível em: <https://pubmed.ncbi.nlm.nih.gov/32235945/>. Acesso em: 22 de Março de 2021.

ZHU, N. et al. A Novel Coronavirus from Patients with Pneumonia in China, 2019. The New England Journal of Medicine, 2020. Disponível em: <https://www.nejm.org/doi/full/10.1056/nejmoa2001017>. Acesso em: 22 de Março de 2021. 